\title{
Die Toten (2016) de Christian Kracht: encenação textual e autoral
}

\author{
[Die Toten (2016) by Christian Kracht: textual and authorial staging]
}

http://dx.doi.org/10.11606/1982-88372238210

\author{
Raquel Meneguzzo ${ }^{1}$
}

\begin{abstract}
The objective of this article is to analyze Christian Kracht's latest novel, Die Toten (The Dead, 2016), from the perspective of textual and authorial staging, that is, examining the text in its linguistic configurations and intertextual relations; and the author in his mediatic presence - which he uses to stage himself in an ambiguous way and to establish relations between his authorial figure and the main character of his novel. The concepts of literary field (BOURDIEU, 1996) and that of paratext (GENETTE, 1989) offer a theoretical framework for this approach. It becomes apparent that Kracht, in Die Toten, applies different strategies to reflect about his own work.
\end{abstract}

Keywords: Christian Kracht; The Dead; staging; contemporary literature.

Resumo: O objetivo deste artigo é analisar o último romance de Christian Kracht, Die Toten (Os Mortos, 2016), a partir da ótica da encenação textual e autoral, ou seja, examinando o texto em suas configurações linguísticas e relações intertextuais; e o autor em sua presença midiática - através da qual se encena de modo ambíguo e estabelece relações entre sua figura autoral e o personagem principal de sua obra. O conceito de campo literário de Bourdieu (1996) e de paratexto de Genette (1989) oferecem subsídios teóricos para a abordagem feita. Percebe-se que Kracht, em Die Toten, utiliza várias estratégias para refletir sobre a própria obra.

Palavras-chave: Christian Kracht; Os Mortos; encenação; literatura contemporânea.

\section{Introdução}

Como Christian Kracht não é muito conhecido fora de países de língua alemã, faz-se necessária uma breve apresentação do autor. Ainda que suas outras publicações não sejam tema deste artigo, um panorama de sua atuação revela, ao menos em parte, seu posicionamento no campo literário, importante para a análise posterior. Christian Kracht é

1 Universidade Federal do Rio Grande do Sul (UFRGS) - Campus do Vale, Av. Bento Gonçalves, 9500, Agronomia, RS, 91540-000, Brasil. E-mail: raquelmeneguzzo@gmail.com. ORCID: 0000-0002-23559267

\section{(cc) BY-NC}

Pandaemonium, São Paulo, v. 22, n. 38, set.-dez. 2019, p. 210-235 
Meneguzzo, R. - Die Toten (2016) de Christian Kracht

um escritor suíço que inicia sua carreira como jornalista em 1989 na revista Tempo, uma revista alemã sobre moda e cultura pop que lhe permite fazer experimentos com o new journalism. Mais tarde escreve colunas para outros jornais alemães, como Der Spiegel, Welt am Sonntag e Frankfurter Allgemeine Zeitung (FAZ), mas seu debut literário acontece em 1995 - ano em que encerra suas atividades na Tempo - com a publicação de Faserland. A partir de então, o autor se torna uma figura controversa nas mídias, principalmente entre os críticos jornalísticos, porém alcança um público relativamente grande e desperta o interesse dos estudos literários.

Após Faserland, publica os romances 1979 em 2001, Ich werde hier sein im Sonnenschein und im Schatten em 2008, Imperium em 2012 e Die Toten em 2016, dos quais Imperium é o que recebe mais atenção da crítica e do público, tendo sido traduzido para mais de quinze línguas, adaptado para teatro, e agraciado com dois prêmios de literatura ainda no ano de lançamento (Grosser Literaturpreis von Stadt und Kanton Bern e Wilhelm-RaabeLiteraturpreis) e um prêmio em 2016 por sua tradução para o inglês (Helen \& Kurt Wolff Prize para o tradutor Daniel Bowles). Não obstante, por ocasião de seu lançamento, Kracht é acusado por Georg Diez, resenhista da revista Der Spiegel, de permear seu romance com pensamentos de extrema direita. Encontrando pouco material para embasar sua opinião no próprio romance, Diez utiliza outros escritos de Kracht, deslocando-os de seu contexto, para fazê-lo. Ainda que infundada, tal resenha provoca tumulto na imprensa: outros jornalistas defendem o autor, escritores - como Elfriede Jelinek, Daniel Kehlmann e Uwe Timm -, assinam um abaixo-assinado em prol da liberdade de expressão, e Kracht cancela suas sessões de leitura na Alemanha. Como consequência, tal acontecimento aumenta a projeção midiática do livro e do autor, colaborando para despertar o interesse por sua obra e pessoa ${ }^{2}$.

Também seu último romance, Die Toten (Os Mortos), mesmo que acusado de ser uma moda passageira pelo jornal Tagesspiegel (BARTELS 2016b), é agraciado ainda no ano de lançamento com o prêmio Hermann Hesse (Hermann-Hesse-Literaturpreis) e o prêmio suíço (Schweizer Buchpreis) de literatura. Além dos romances, Kracht possui publicações conjuntas com outros autores, que incluem troca de correspondência, relatos de viagem, conversas, entre outros. Em 2013 escreve, em conjunto com sua esposa e diretora de cinema

\footnotetext{
${ }^{2}$ Uma análise mais detalhada sobre o ocorrido pode ser encontrada em Korfmann (2014).

Pandaemonium, São Paulo, v. 22, n. 38, set.-dez. 2019, p. 210-235
} 
Frauke Finsterwalder, o roteiro para o filme Finsterworld, pelo qual recebe o prêmio de melhor roteiro da Deutsche Filmkritik.

O interesse pela obra de Christian Kracht não se deve somente à obra em si, mas também à figura do autor, cuja forma de se apresentar em público é ambígua. De modo geral, ele evita que seja possível criar uma imagem unívoca de si, se mostrando ora tímido, ora arrogante, ora desdizendo afirmações anteriores, ora fazendo afirmações paradoxais em si mesmas, ora insinuando semelhanças entre si e suas personagens. Se, de início, tal programa gera perplexidade ou antipatia - motivo pelo qual Faserland é tão controversamente recebido pela crítica jornalística -, hoje já se espera de Kracht que suas entrevistas sejam pouco esclarecedoras, contraditórias, paradoxais e fortemente estilizadas. Há até certa curiosidade e expectativa, já que aparições públicas não são muito frequentes. Assim, em 2018, quando confere um ciclo de três palestras em Frankfurt a convite da Universidade Goethe, lemos em jornais sobre a "palestra ansiosamente aguardada" (TAGESSPIEGEL 2018), que "em raras ocasiões a expectativa sobre as declarações de um autor foram tão grandes" (TAZ 2018), e para a qual Miriam Zeh e Kevin Kempke afirmam chegar com duas horas de antecedência para evitar quaisquer imprevistos provocados pelo fã-clube do autor (MERKUR 2018).

O objetivo deste artigo é analisar o último romance de Christian Kracht, Die Toten, publicado em 2016, a partir da ótica da encenação textual e autoral, ou seja, investigar o texto a partir de suas configurações linguísticas e relações intertextuais e sua relação com a figura autoral em suas aparições midiáticas. Com Bourdieu (1996), partiu-se do pressuposto de que os escritores se utilizam de suas obras e figuras públicas para se estabelecer no campo literário, ou seja, arranjam - ou encenam - os elementos de suas obras e entram em cena como autores de uma forma específica, procurando se distinguir e se destacar de outros agentes do campo. Também foi partilhada a ideia de que elementos exteriores à obra, mas a ela relacionados, são relevantes para sua interpretação (GENETTE 1989). Genette (1989: 1011) denomina tais elementos de paratextos, e os divide em peritextos - os que se encontram na materialidade do texto, como título, capa, prefácio, etc. - e epitextos - informações que comentam, explicam ou criticam o texto em mídias ou âmbito privado, como entrevistas, cartas, diários, resenhas, etc.

\footnotetext{
${ }^{3}$ Todas as traduções são da autora.

Pandaemonium, São Paulo, v. 22, n. 38, set.-dez. 2019, p. 210-235
} 
Meneguzzo, R. - Die Toten (2016) de Christian Kracht

No caso de Christian Kracht, lida-se com um autor consciente de sua encenação, e que faz uma observação de segunda ordem, ou seja, utiliza sua encenação - dentro e fora de sua obra - para chamar atenção para o caráter encenatório do próprio campo em que atua. Assim, no âmbito da encenação textual, é apresentado um breve resumo do enredo, são identificadas algumas das relações intertextuais com os romances anteriores de Kracht, com outras obras literárias e com outras mídias, neste caso, teatro e cinema. Já no âmbito da encenação autoral, deteve-se sobre a publicação do livro, as entrevistas concedidas pelo autor por sua ocasião, e a série de palestras que profere na Universidade Goethe, em Frankfurt. Permeando a discussão estão as relações entre a encenação textual e a autoral, isto é, as conexões que Kracht estabelece no romance com sua figura autoral e vice-versa, em suas aparições públicas com o romance. Pretende-se verificar se o autor dá continuidade às práticas encenatórias que empreende desde a publicação de Faserland - que consistem em jogos de autorreflexividade, ambiguidades e encenação de sua figura pública -, e avaliar brevemente que outras estratégias ele emprega nesse romance.

\section{Encenação textual}

Optou-se por iniciar com um resumo prolongado do texto para que alguns aspectos discutidos a seguir possam ser conferidos e porque, como não há tradução do livro para o português, o romance é de difícil acesso no Brasil. Um aspecto que chama atenção é a configuração de personagens e acontecimentos históricos no romance, mas esse aspecto não será discutido neste texto. O enredo do romance se passa em Berlim, no Japão, na Suíça e em Los Angeles (atual local de residência do autor) no início da década de 1930, e o romance é dividido em três partes de acordo com o princípio jo-ha-kyu do teatro nô ${ }^{4}$. Tais partes, por sua vez, consistem em pequenos capítulos, os quais, como cenas em um filme que se utiliza de crosscutting, alternam entre linhas da narrativa. Na primeira parte há a introdução às personagens principais, o diretor suíço de cinema Emil Nägeli, o funcionário público japonês Masahiko Amakasu, e a noiva de Nägeli e aspirante a atriz Ida von Üxküll. Em seguida, são apresentados episódios da infância e da juventude de Nägeli e de Amakasu. Já na segunda

4 Teatro tradicional japonês, normalmente dividido em três partes, cujo palco possui formato de "L", e em cujas performances os atores frequentemente usam máscaras. (Leiter 2006: 310-311).

Pandaemonium, São Paulo, v. 22, n. 38, set.-dez. 2019, p. 210-235 
Meneguzzo, R. - Die Toten (2016) de Christian Kracht

parte, o diretor recebe um convite de Alfred Hugenberg, diretor da então maior rede alemã de estúdios cinematográficos, a Universum Film AG (UFA) para realizar um filme no Japão, em uma parceria entre os dois países. Após uma noite de bebedeira com os críticos Siegfried Kracauer e Lotte Eisner, que o convencem a pedir aumento do orçamento e transformar o filme - inicialmente pensado para ser uma comédia estrelando Heinz Rühmann - em um filme de suspense, uma "alegoria do horror que está por vir", Nägeli parte para o Japão, ansioso por reencontrar sua noiva, que lá a encontra. Ele não sabe, no entanto, que a ideia para a produção do filme partira de Amakasu, que enviara uma carta a Hugenberg - junto da gravação de um seppuku, um ritual japonês de suicídio - propondo que os dois países se unissem para lutar contra o imperialismo cultural americano.

Amakasu e Ida se conhecem na comitiva de recepção de Charles Chaplin, em uma de suas viagens ao Japão, e à noite os três se juntam ao filho do primeiro ministro Tsuyoshi Inukai e assistem juntos uma peça de teatro nô. No dia seguinte recebem a notícia do atentado que matara o primeiro ministro - e que deveria ter matado seu filho e Chaplin também. Amakasu e Ida iniciam um relacionamento e se estabelecem na mansão alugada pelo funcionário para as gravações enquanto esperam a chegada de Nägeli. O diretor sugere que eles sejam os atores principais e passa a filmá-los com uma câmera portátil, com a qual flagra a traição. Então Nägeli parte a esmo pelo Japão, filmando aquilo e aqueles que cruzam seu caminho.

Na terceira parte, Chaplin, Ida e Amakasu se encontram em um navio rumo aos Estados Unidos, pois Chaplin assegura que ela será uma atriz muito famosa. Após uma discussão, Chaplin se aproveita de um momento a sós com Amakasu e o força a se jogar em alto mar; Ida fracassa em carreira cinematográfica e se joga de cima da letra $\mathrm{H}$ do letreiro de Hollywood; e Nägeli retorna para a Suíça, onde apresenta seu novo filme, homônimo ao livro, e se consagra como diretor entre os críticos, ainda que parte do público adormeça durante a exibição.

Há elementos que ligam Die Toten aos romances anteriores do autor. Motivos recorrentes, como episódios envolvendo fluidos corporais, o ligam a Faserland, 1979 (excrementos) e Ich werden hier sein... (saliva). Situações análogas podem ser encontradas também, por exemplo, no destino do protagonista de 1979 e Putzi Haenfstaengl, que perecem em campos de trabalhos forçados. No entanto, mais nítida é a relação com Imperium, que se Pandaemonium, São Paulo, v. 22, n. 38, set.-dez. 2019, p. 210-235 
Meneguzzo, R. - Die Toten (2016) de Christian Kracht

estreita estilística, temática e historicamente. Imperium narra a história de um personagem marginal da história alemã chamada August Engelhardt. Ele se muda para a ilha de Kabakon, no Pacífico (hoje Papua-Nova Guiné) para fundar a Ordem do Sol, uma seita pseudorreligiosa com o objetivo de deificar o homem através do nudismo e da ingestão de cocos. Após o fracasso de sua empreitada, Engelhardt é encontrado por soldados americanos que o levam aos Estados Unidos, onde a narrativa de sua vida é transformada em filme.

Estilisticamente, os dois romances são os únicos que possuem um narrador extradiegético e incorporam figuras históricas como personagens do enredo. Também adquirem um caráter recursivo, porque seu final reflete o início. Em Imperium, a descrição do filme sobre a vida de Engelhardt repete as primeiras linhas do romance, e em Die Toten, tanto a primeira quanto a última cenas são descrições de suicídios. O personagem principal de Die Toten parece entrar em cena no fim de Imperium, já que, no fim deste livro, o diretor aparece na primeira fila da sala de cinema. Uma personagem histórica presente nos dois romances é Wilhelm Solf, que em Imperium exige o "fim ao estado de indisciplina" na colônia alemã, e em Die Toten decide proteger Amakasu e facilitar sua entrada para o ministério japonês. Em relação à temática, ambos tratam de impérios: a Alemanha como colonizadora de territórios em outros continentes, o imperialismo político e cultural americano, o nacional-socialismo (o terceiro império, das dritte Reich), e, em sentido mais amplo, a obra artística como império regido pelo próprio artista. Historicamente, Die Toten, situado no início do século XX, é uma continuação temporal de Imperium, que se passa no século XIX.

As relações com outras obras - que não do próprio autor - são abundantes, e não se pretende esgotar as relações intertextuais do romance, mas apontar algumas que demonstrem os diversos modos em que são estabelecidas. Algumas relações são mais explícitas, ou mais complexas, outras menos. Algumas fazem referência ao cânone ocidental, outras a obras menos conhecidas. Algumas, também, fazem referência apenas ao nome de algum autor, transformando-o em um substantivo, e permitem ao leitor que preencha seu sentido com seus conhecimentos prévios, como "esquecimento dostoievskiano de si próprio" (KRACHT 2016a: 27), “zona hölderliniana" (KRACHT 2016a: 30) e "segredos eichendorffianos" (KRACHT 2016a: 84). 
Meneguzzo, R. - Die Toten (2016) de Christian Kracht

O romance é homônimo ao último conto de Dubliners, primeiro livro em prosa publicado pelo escritor irlandês James Joyce, em 1914. Nesse conto, Gabriel Conroy e sua esposa Gretta comparecem à festa de Natal que reúne família e amigos na casa de suas tias. Os convidados dançam, cantam, conversam e por fim dispersam-se. O casal retorna para o hotel, onde as intenções de Gabriel de passar uma noite romântica com sua esposa são frustradas ao ouvir a história de Michael Furey. Gretta conta para Gabriel que uma música cantada na festa lhe trouxera a memória do jovem, e que acredita que ele tenha morrido de amor por ela. Gretta chora na cama e adormece, enquanto Gabriel se descobre enciumado, conjecturando sobre a vida e a morte, até que adormece ouvindo a neve cair. O conto termina com a expressão "os mortos", refletindo o título, conferindo recursividade ao texto e sugerindo o caráter cíclico da vida humana e sua relação com o passado, que se presentifica através da memória e do sonho. É esse o aspecto que se torna relevante em Die Toten, já que a referência explícita se expressa na passagem em que Ida dorme e "adentra por um breve momento e um pouco temerosa o reino dos mortos, um mundo intermediário no qual sonho, filme e lembrança infestam uns aos outros" (KRACHT 2016a: 173), assim como Gabriel deitado em sua cama, cuja alma alcança "a região em que habitam as vastas hordas dos mortos" (JOYCE 2005: 205).

Uma adaptação do conto de Joyce para o cinema acontece em 1987, dirigida por John Huston, que falece logo após terminar o filme, ainda antes de ele estrear no cinema. Homônimo ao texto, o filme encena seus aspectos através de recursos audiovisuais, assim, sugerindo a presentificação do passado, uma terceira sombra atravessa a tela enquanto Gretta e Gabriel sobem para o quarto no hotel. O romance alude à autobiografia de John Huston, Um Livro Aberto, publicado em 1980. Em seu texto, o diretor conta ter ateado fogo a uma escola e ter recebido a visita de Charles Chaplin quando jovem. Amakasu também ateia fogo à sua escola e recebe Chaplin em sua visita ao Japão. Huston conta inclusive que nessa visita, Chaplin teria lhe explicado como em um filme "alguém poderia pular de um trampolim de mergulho e, logo antes de cair na água, inverter a direção e voltar a ficar de pé” (HUSTON: 1980: 18). Já em Die Toten, Chaplin força Amakasu a se lançar do navio em alto-mar, o que leva o oficial à morte.

Em Die Toten, duas das personagens principais cometem suicídio, um dos quais encerra o livro, já o suicídio que abre o romance não é cometido por um personagem Pandaemonium, São Paulo, v. 22, n. 38, set.-dez. 2019, p. 210-235 
Meneguzzo, R. - Die Toten (2016) de Christian Kracht

relevante, e sim por um oficial japonês qualquer. A relevância dessa cena está antes na referência ao escritor e diretor japonês Yukio Mishima. Mishima roteirizou e dirigiu Yukoku: The Rite of Love and Death em 1966, baseado em um conto de autoria própria parcialmente homônimo, o conto se chama apenas patriotismo (MISHIMA 1977), estrelado por si próprio e por sua mulher. Encenado em um palco nô, o filme conta a história de um oficial japonês a quem é atribuída a tarefa de matar um grupo de militares após um golpe de estado malogrado. No entanto, percebendo que cumprir tais ordens o torna um amigo desonroso e não as cumprir um oficial desonroso, vê-se obrigado a matar-se honrosamente - cometendo seppuku - e ser seguido por sua esposa, que se mata após assistir o suicídio do marido. Curiosamente, apenas quatro anos depois, o próprio Mishima comete seppuku após proferir um discurso em favor do retorno do poder ao imperador japonês (STOKES 2000; FLANAGAN 2014).

No livro de Kracht, uma citação famosa de Flaubert (1876) tem duas palavras trocadas de lugar e assume novo significado. Na citação original, em uma carta a Gertrude Tennant, lê-se: "Sejam metódicos e organizados em suas vidas, como um burguês, para que possam ser violentos e originais em suas obras". Nägeli, que reclama que mesmo os lugares-comuns franceses são falsos, troca "metódicos e organizados" por "violentos e originais" (KRACHT 2016a: 40). A nível intradiegético, Nägeli resulta correto já que, estando a citação invertida em seus elementos, ela se torna falsa.

Inúmeras passagens fazem alusão à Morte em Veneza, de Thomas Mann. Já no início, Nägeli "sente um afrouxamento geral, uma fleumatização do corpo" (KRACHT 2016a: 18) da mesma forma que Aschenbach "ante o crescente desgaste de suas forças" (MANN 2003: 5) decide viajar - só que o escritor não vai para o Japão, e sim para Veneza. Nägeli, antes de se reencontrar com sua noiva, adentra um salão de beleza e se deixa maquiar pelo sensei, pelo “mestre do rejuvenescimento" (KRACHT 2016a: 157), que pede para Nägeli se sentar:

e começa delineando cuidadosamente, com um lápis preto, a curvatura das sobrancelhas, mergulha brevemente o pincel em um pote cheio de um creme vermelho escarlate, e então colore as bochechas do suíço, enquanto as articulações de seus dedos limpam o excesso de cor habilmente, com movimentos circulares e delicados (KRACHT 2016a: 157).

O mesmo fizera Aschenbach em Veneza, após apaixonar-se por Tadzio:

Aschenbach [...] viu no espelho suas sobrancelhas se arquearem mais decididas e harmoniosas, o corte de seus olhos se alongar, seu brilho ser ressaltado com um leve toque de pintura nas pálpebras; viu despontar mais abaixo, onde a pele fora escura e opaca como couro, um carmim delicado, suavemente aplicado, seus lábios exangues de há pouco se

Pandaemonium, São Paulo, v. 22, n. 38, set.-dez. 2019, p. 210-235 
Meneguzzo, R. - Die Toten (2016) de Christian Kracht

intumesceram num tom de framboesa, as rugas das faces, da boca, dos olhos desapareceram sob o creme e o aroma da juventude (MANN 2003: 88).

Diferente de Aschenbach, no entanto, Nägeli não morre no final do romance, ao contrário, é a única das personagens centrais que permanece viva, volta para a Suíça e então vive uma vida pacata, gozando do prestígio artístico, como Aschenbach no início da novela, ou até mesmo o próprio Thomas Mann.

As três personagens principais ouvem o som hah ser proferido: Nägeli de seu pai no leito de morte, Amakasu do homem na caverna aos pés das falésias de Tojinbo e Ida em seu sonho. Nessa mesma ordem no romance, o som perde materialidade a cada vez que aparece. Primeiro, é pronunciado pelo pai de Nägeli, uma pessoa à beira da morte, mas ainda assim uma pessoa. Em seguida, por um homem gigantesco cujo rosto fica encoberto por sombras após "fissuras no tempo" (KRACHT 2016a: 76), de modo que se possa duvidar de sua existência concreta e, por fim, não há um emissor, Ida ouve apenas um "sopro insubstancial” (KRACHT 2016a: 173). A sequência de letras utilizadas para grafar o som, ainda que perca em materialidade, continua sendo pronunciada da mesma forma. Assim, além de ser o som misterioso que as personagens não conseguem decifrar, hah, com uma letra a menos $(h a)$, é o nome da segunda parte do livro, e, com suas letras a menos $(h)$, é o nome da oitava letra do alfabeto em alemão. Nesse sentido, a letra $h$ pode ser vista como uma inicial para Hitler que, em 1932 se torna cidadão alemão, anuncia sua candidatura à presidência (p. HAUNER 2008: 79-80) ou para Hölderlin, citado no final do romance. Atribuída a uma frase de jornal que noticiaria a morte de Ida, "ela foi como fogo adormecido sobre as pedras de silício" (KRACHT 2016a: 213) reproduz quase literalmente uma passagem de Hyperion:

Nós somos como fogo adormecido em troncos ressequidos ou em silício; e procuramos ininterruptamente o fim da prisão exígua. Mas eles vêm, e ele compensam eras de luta, os momentos de libertação, nos quais o divino irrompe do cárcere, nos quais a chama se desprende da madeira e se alça vitoriosa por sobre as cinzas, há! nos quais temos a impressão de que o espírito liberto, esquecido das penas, dos contornos da servidão, voltasse triunfante aos palácios do sol (HÖLDERLIN 1979: 16).

E, conferindo a citação de Hölderin nos deparamos com outro hah, dessa vez exclamatório, no entanto, o hah de Hölderin incita aos céus, e o de Ida a despenha no chão.

Ida von Üxküll é parcialmente o nome de Elisabeth Olga Ida von UexküllGyllenband, nascida em 1911 em Viena, filha de Nikolaus Graf von Üxküll-Gyllenband, preso pela Gestapo e morto após uma tentativa malograda de derrubar o governo de Hitler Pandaemonium, São Paulo, v. 22, n. 38, set.-dez. 2019, p. 210-235 
Meneguzzo, R. - Die Toten (2016) de Christian Kracht

(TUCHEL 2016). O suicídio da personagem, no entanto, é claramente inspirado na história de Peg Entwistle, que pula da letra "h" da placa de Hollywood em setembro de 1932 (THE LEWISTON DAILY SuN 1932), época na qual se passa a história. O nome de Amakasu faz referência ao personagem histórico Masahiko Amakasu, um oficial do exército japonês que entra na história em 1923, ocasião em que tortura e assassina dois anarquistas e uma criança. Condenado a dez anos de prisão, mas solto após três, é enviado para a França às custas do governo japonês para estudar, onde trava contato com militares alemães. Em 1936 visita os estúdios da UFA em Babelsberg e em 1937 assume o comando do estúdio de filmes Man’ei, realizador de filmes propagandísticos, enquanto mantém contato com a UFA, inclusive realizando coproduções (SIEREK 2018; BASKETT 2008).

Já o nome do personagem principal faz referência ao escritor norueguês Knut Hamsun, que figura como personagem secundário no romance. Antes de viajar para o Japão, Nägeli viaja até a Noruega para acertar a adaptação do romance Mistérios, de Hamsun, mas o escritor o deixa esperando enquanto faz ioga, e o filme não é realizado. Mistérios conta a história de um homem que se instala em um hotel num pequeno vilarejo e passa a chamar a atenção dos moradores com seu comportamento atípico. Tal homem se chama Nagel, prego ou unha em alemão (coincidentemente, Nägeli tem o hábito de roer as unhas), cuja forma diminutiva - em sua variante suíça, principalmente - pode ser Nägeli, e conforme aponta Robert Ferguson (1987: 133), autor de uma biografia de Hamsun, anagrama para en gal, um homem louco em norueguês, e angel, anjo em inglês. Nagel, assim como Kracht, chama atenção por se contradizer em suas opiniões, por ter opiniões completamente diversas a dos outros, e por revelar quase nada sobre si próprio. O sobrenome de Nägeli também coincide com o de Karl Wilhelm von Nägeli, botânico cujos estudos, em complemento à teoria da evolução, são posteriormente utilizados para embasar os princípios da eugenia e justificar o Holocausto. Já o primeiro nome, Emil, provém do latim, aemulor, aquele que imita, emula, ou seja, aquele que encena, ou, como diria Hamsun sobre Nagel, um poseur (apud FERGUSON 1987: 126). Outra alusão a Mistérios é o episódio em que Amakasu testemunha uma mulher lançando-se de um penhasco, desce as escarpas para verificar o ocorrido, encontra uma mulher abandonada em uma caverna, promete ajuda mas a abandona, e passa a ser assombrado por ela. Em Mistérios, o protagonista sonha com uma mulher jogando-se de um penhasco, e descobre ser seu sonho um prenúncio quando acorda e lhe contam que a mulher

Pandaemonium, São Paulo, v. 22, n. 38, set.-dez. 2019, p. 210-235 
Meneguzzo, R. - Die Toten (2016) de Christian Kracht

que avistara na noite anterior cometera suicídio como em seu sonho. Assim, também o suicídio em Die Toten pode funcionar como um prenúncio do suicídio de Ida, e até mesmo de Amakasu, que não se lança de um precipício ao chão, mas de um navio ao mar.

Além de estarem presentes a nível intradiegético na peça de teatro que Ida e Amakasu assistem e no filme que Nägeli produz, as mídias teatro e cinema são importantes para a estrutura do romance. O romance é dividido em três partes de acordo com o teatro nô, intituladas com os respectivos ideogramas. Essas partes são divididas em episódios alternados, que o narrador por vezes parece descrever através da lente de uma câmera. Samuel Leiter (2006) explica que o teatro nô integra os quatro principais tipos de teatro tradicional japonês e sua origem remonta ao século XIV. O componente rítmico essencial do teatro nô segue o princípio jo-ha-kyu, comumente traduzidos como introdução, desenvolvimento e conclusão, e se refere tanto ao ritmo de desenvolvimento da peça quanto à organização sequencial de um programa (normalmente dividido em cinco cenas). As cenas jo são relativamente lentas e simples, as $h a$ são mais rápidas e complexas, e as $k y u$, por fim, atingem o clímax. No romance, esse princípio estético é explicado por Kono, que elucida também a interpretação da máscara Hannya como revelação de que "o personagem se transformou em um demônio furioso com presas, uma boca escancarada, olhos fundos, e chifres" (LEITER 2006: 300). Assim, o personagem explica também a estrutura do próprio romance, já que a primeira parte, composta por 19 capítulos, introduz Nägeli e Amakasu através de episódios de sua infância e juventude, a segunda, também com 19 capítulos, desenvolve o enredo com a viagem ao Japão, e a terceira, com apenas nove capítulos, leva as personagens à culminação de seus destinos - morte no caso de Ida e Amakasu, e superação do bloqueio criativo no caso de Nägeli. Por fim, a peça que assistem cria um nível hipodiegético que estabelece paralelos com a situação em que se encontram as personagens. Intitulada Kanawa, a peça trata de um triângulo amoroso: uma mulher traída procura vingarse do marido e de sua amante transformando-se em um demônio para matá-los (KINOSHITA s/d). A peça não remete Ida ao triângulo amoroso em que ela própria se encontra, e sim ao livro que Nägeli lhe presenteia em sua chegada, o livro de Ezra Pound sobre o teatro nô (KRACHT 2016a: 166). Nägeli, a parte traída, não precisa transformar-se em um demônio para matar os adúlteros porque ambos cometem suicídio, mas canaliza os seus sentimentos para a produção de sua obra.

Pandaemonium, São Paulo, v. 22, n. 38, set.-dez. 2019, p. 210-235 
Meneguzzo, R. - Die Toten (2016) de Christian Kracht

O jogo textual que envolve o universo filmográfico, no entanto, não se estabelece apenas através do fato de Nägeli ser diretor de cinema. Tal fato é central para a obra, pois o "eixo de celuloide" que Amakasu pretende estabelecer com a Alemanha serve de prenúncio para o eixo estabelecido pelos dois países durante a Segunda Guerra Mundial, e reflete a ideologia nazista, conforme a crítica de cinema Lotte Eisner, também personagem do romance, afirma em The Haunted Screen: "Em seus primeiros discursos, proferidos em 1933/34, Goebbels declarou que o cinema alemão tinha a missão de conquistar o mundo como a vanguarda das tropas nazistas" (EISNER 1969: 329). Mas, assim como em Imperium, há passagens no texto que indicam a possibilidade de a própria obra se tratar de um filme, como o momento em que Nägeli percebe estar "tanto na frente quanto atrás da câmera" (KRACHT 2016a 16), ou quando Chaplin, a bordo do navio para os Estados Unidos, guia Amakasu "para onde não possam ser ouvidos, para trás da tela" (KRACHT 2016a: 191-192). De modo mais sutil, os olhos podem substituir a câmera: "A íris azul-clara de seu olho junto ao buraco, iluminada através do cenário no quarto, quase como se seu próprio olhar fosse o projetor de tal abominação" (KRACHT 2016a: 177). Essa última passagem parece fazer alusão à primeira cena do livro, na qual um seppuku é filmado através de uma câmera instalada em um buraco na parede de um quarto.

Ainda, o próprio romance sugere tratar-se de um filme, já que, quando Nägeli pensa sobre o filme que quer fazer, decide:

Ele deve criar algo que seja altamente artificial, e ao mesmo tempo que faça referência a si próprio. [...] Agora ele deve realmente criar algo patético, fazer um filme que seja reconhecivelmente artificial e que seja recebido pelo público como afetado e, principalmente, deslocado. (KRACHT 2016a: 153)

Tal passagem estabelece paralelos entre os níveis intra e extradiegéticos. Ao mesmo tempo que se refere ao programa que Nägeli traça para a produção de seu filme, parece se referir ao programa que Kracht traça para a construção de seu romance. A obra reflete a si própria nas duas acepções da palavra. Ao mesmo tempo em que a passagem medita metanarrativamente sobre sua própria concepção, o filme de Nägeli reflete o romance assim como um espelho - ou uma tela de cinema - reflete a luz que incide sobre ele. É através dos paralelos com o cinema que o romance explora a autorreferencialidade e a metanarratividade, criando uma narrativa em abismo. 
Meneguzzo, R. - Die Toten (2016) de Christian Kracht

A mise en abyme aparece ainda no enredo, quando Nägeli visita o salão de beleza. Ele é posicionado entre dois espelhos, de modo que as imagens se refletem ad infinitum. Christine Riniker (2018) aponta que essa passagem, no meio da segunda parte, marca o eixo estrutural de reflexão do próprio romance, de modo que passagens e elementos anteriores a ele refletem outros posteriores. Assim, as cenas inicial e final de suicídio; os buracos na parede pelos quais a câmera registra um suicídio e o olho de Nägeli a traição; as facas tantō, que cortam a barriga do oficial que comete seppuku e o bife que Amakasu ingere cru; fi-di-bus, o apelido de infância de Nägeli e o chilro de um pássaro mecânico quando este deixa o salão de beleza; as sílabas ve-ri-tas nos cubos de gelo do copo de Hugenberg e nas bolas de golfe de Chaplin; o lápis lilás com o qual o pai de Nägeli escreve e que se materializa no escritório de Hugenberg para depois aparecer no táxi de Nägeli e no campo de trabalhos forçados de Hanfstaengl; e, finalmente, a focalização dupla das férias que Nägeli e Ida passam juntos.

Antes do "eixo reflexivo", a narrativa focaliza a memória de Nägeli sobre o ocorrido:

Ele fora se refrescar na água, quando, de repente, o vórtice esmeraldino de uma onda o apanhara e o sugara para baixo, e ele, em meio a tropeços e resfôlegos, voltara a emergir contente sob a irisante luz veranil; com a mão erguida em um aceno tranquilizante, vira-a de pé na praia, morena do sol em um traje de banho azul-marinho, os graciosos dedos do pé enterrados quase pela metade na areia, as mãos esguias sobre a boca aberta de medo por ele; então, quando vira Nägeli são e salvo, sorrira aliviada. (KRACHT 2016a: 82)

Quando o episódio é focalizado através de Ida, entretanto, percebemos que seu sorriso, interpretado como alívio, parece antes chacota, já que o que conta a Amakasu é que

ele costumava pentear os cabelos laterais sobre o topo de sua cabeça calva, ela nunca reparara nisso, até o dia em que, estando de férias na praia (eles se banhavam no mar Báltico, que ainda estava dolorosamente gelado para o fim de junho), Nägeli fora surpreendido por uma forte onda que o atingira nas costas, o fizera tropeçar, cambalear e esquecer de encolher a barriga nesse meio-tempo. Quando levantara os braços rindo e cuspindo chafarizes de água com o intuito de cumprimentá-la, ela vira as madeixas de cabelo compridas até o ombro, que lhe desciam e pingavam frouxamente das têmporas - além dessas repugnantes extensões capilares e alguns chumaços espalhados aqui e ali, ele era praticamente careca. Ele parecera um palhaço de circo tolamente acidentado, tristemente ansioso por um pouco de aplauso, o coitado. (KRACHT 2016a: 161)

Os episódios parecem exercer mais de uma função. Por um lado, demonstram o descompasso do relacionamento das personagens, que culmina na traição por parte de Ida; por outro, parecem apontar para a impossibilidade de um relato que se exima de subjetividade. A voz do narrador, na maior parte do romance, parece ser a de um narrador onisciente, mas essa ilusão é quebrada por comentários que parecem deslocados ou Pandaemonium, São Paulo, v. 22, n. 38, set.-dez. 2019, p. 210-235 
Meneguzzo, R. - Die Toten (2016) de Christian Kracht

ambíguos, de início mais escassos, mas cuja frequência aumenta ao longo da narração. Ora há mudança brusca de registro, ora metalepse, comentários entre parênteses, ora pensamentos e falas das personagens se confundem com as opiniões de um narrador que não se comporta univocamente. Assim, o uso súbito da primeira pessoa do plural chama a atenção do leitor em "havia coisas que não deveriam ser registradas nem reproduzidas, havia acontecimentos dos quais nós nos tornamos cúmplices ao contemplar sua reprodução, já havia acontecido o suficiente, estava tudo lá" (KRACHT 2016a: 24), e não fica claro se se trata do pensamento do personagem ou de metalepse. Já em "Nägeli viaja, como bem lembramos, em um avião periclitante" (KRACHT 2016a: 106), o pronome é preciso e apenas relembra o leitor de estar lendo um livro, técnica amplamente usada em romances realistas. Outras passagens modalizam a narração, como se o narrador - como uma câmera - estivesse limitado a um enquadramento específico, ou como se não conseguisse decidir o que seria mais adequado para acontecer no momento, por exemplo em "ele suprimiu a vontade de fumar, pode ser que com isso um único e distraído som tenha se projetado de seus lábios apertados” (KRACHT 2016a: 61); “opa, opa, podia ser que já tivesse tomado saquê demais” (KRACHT 2016a: 101); "será que ele consegue suspeitar que exatamente neste momento sua mãe, notavelmente fotogênica, morre [...]?" (KRACHT 2016a: 156); “é bem possível que ele tenha voltado a chorar" (KRACHT 2016a: 182); ou, ainda, "ela sorriu para ele, seria demais dizer que o fez apaixonadamente, ou talvez não" (KRACHT 2016a: 188).

Há uma passagem em que o narrador avalia a opinião antissemita de um personagem: "Do banco da frente o motorista de táxi, com seu sotaque covarde e resmungado, diz algo muito feio" (KRACHT 2016a: 118). Ela chama a atenção do leitor por se assemelhar ao modo como adultos se expressam com crianças ao ensiná-las que algo é errado, ou ao modo como as pessoas repreendem verbalmente crianças ou cachorros, denominando algo "muito feio". Tal expressão pode criar um efeito de comicidade ou irritação por si só, mas ela também pode ser vista como referência às acusações feitas por Diez na revista Der Spiegel. Para antecipar quaisquer acusações, já constam comentários explícitos no romance sobre o distanciamento em relação a "opiniões de extrema direita". Assim, mesmo que alguém queira atribuir a voz do narrador ao próprio autor, acusações deste teor são revidadas de antemão. Não só o livro responde à recepção de obras anteriores do autor, como também antecipa a sua própria nas 
Meneguzzo, R. - Die Toten (2016) de Christian Kracht

passagens em que estabelece paralelos entre si e o filme de Nägeli e o caracteriza como "artificial" e "autorreferencial".

Percebemos que Die Toten estabelece relações intertextuais com diversas obras, possui uma construção em mise en abyme, incorpora as mídias cinema e teatro a nível intra e extradiegético e utiliza todos esses elementos para refletir metanarrativamente sobre si próprio. No entanto, percebemos que, além disso, elementos paratextuais se tornam relevantes para a obra, como a recepção jornalística. Interessa-nos, assim, analisar tais paratextos que incluem as encenações da figura pública do escritor e verificar de que modo elas estabelecem relações com o próprio romance.

\section{Encenação autoral}

Ainda antes de ser lançado, o romance provoca tumulto na imprensa. A data prevista para publicação é 08 de setembro de 2016, e pouco mais de uma semana antes, no dia 29 de agosto de 2016, o escritor concede uma entrevista ao crítico Denis Scheck para o programa Druckfrisch (CHRISTIAN 2016), como já havia feito por ocasião do lançamento de seus últimos três romances. Exatamente uma semana antes do lançamento, no dia 01 de setembro de 2016, a revista semanal Die Zeit publica um artigo resultante de um encontro com o escritor no café Odeon, em Zurique. O texto mistura relatos e impressões do chefe de redação da revista - descreve o local, as roupas de Kracht, o prato pedido no restaurante -, relata a conversa que teve com o escritor - sobre seu livro, sobre literatura e sobre assuntos diversos - e termina com uma resenha crítica sobre o romance.

No dia seguinte, 02 de setembro de 2016, Jürgen Kaube (2016) critica, no jornal Frankfurter Allgemeine, tanto Scheck quanto Die Zeit. Afirma que a editora do romance haveria enviado cópias para os jornais, mas pedido para que assinassem um termo que não consentiria publicação de resenhas até determinada data e que, antes do fim desse prazo, Scheck haveria realizado tal entrevista por ser amigo do escritor. O comportamento de Scheck, segue Kaube, não denotaria sua postura como crítico literário, pois sua intenção seria antes promover a venda do romance, visto que se contentara com as respostas paradoxais do autor e afirmara que ele seria revolucionário, do mesmo modo como o filme sonoro havia revolucionado o cinema. Em relação à entrevista concedida ao Die Zeit, entre aspas no texto Pandaemonium, São Paulo, v. 22, n. 38, set.-dez. 2019, p. 210-235 
Meneguzzo, R. - Die Toten (2016) de Christian Kracht

de Kaube, acusa o jornal de descrever uma conversa com o autor que negligenciaria a obra. O fato de considerar supérfluas informações, como detalhes sobre a aparência do autor, deixa claro que Kaube não estabelece - deliberadamente ou não - uma relação entre a encenação do autor e a da obra. Apesar de ter assinado o termo que não permitia a publicação de resenhas até a data de publicação do livro, conforme informa Gerrit Bartels em um texto para o Der Tagesspiegel em 10 de setembro (BARTELS 2016a), o FAZ publica sua resenha sobre o livro em 03 de setembro de 2016, que, com exceção da legenda de uma foto do autor ("Christian Kracht por vezes também gosta de usar a gravata solta, conforme informações atuais da crítica literária"), não faz menção alguma ao "escândalo".

A tréplica acontece no dia anterior ao lançamento do livro, 07 de setembro de 2016, no programa "Kulturzeit", da emissora 3sat. Scheck nega que seja amigo de Kracht e insinua que o motivo da irritação de Kaube estivesse atrelado ao fato de não ter conseguido uma entrevista com o suíço. Além do mais, segue o crítico, a entrevista-conversa com o autor de um livro (Porträt) já teria se estabelecido na mídia como gênero audiovisual, e que Kracht não desse respostas satisfatórias sobre suas perguntas não constituiria um fenômeno novo, pois além dessa ser uma marca do escritor, ele não figura entre os únicos a proceder de tal modo.

Uma crítica elegante é feita por Gerrit Bartels (2016a), três dias após publicar sua própria resenha sobre o romance. Depois de explicar a polêmica brevemente, e ressaltar a concorrência entre os jornais e revistas para serem os primeiros a publicar uma resenha sobre o lançamento de um livro importante, encerra o texto levantando a hipótese de que o livro até possa ser objeto de cobiça da imprensa no momento do lançamento, mas que talvez tais estratégias sejam necessárias justamente porque não se sabe se o romance resistirá, por si só, à força do tempo.

Johannes Franzen, resumindo o texto de Kaube, toca em um ponto importante: "Para obter acesso aos exemplares exclusivamente destinados a resenhas, algumas mídias teriam se submetido ao jogo de encenações autorais de modo demasiadamente subalterno" (2017: 90). Se o fazem de modo subalterno ou não, não é de nosso interesse investigar, mas, de fato, o procedimento da editora e do autor de Die Toten desestabiliza sua relação com a crítica jornalística, que é comumente vista como detentora do poder de condenar ou alavancar o sucesso de um título. A pequena alteração no procedimento de mandar as cópias dos Pandaemonium, São Paulo, v. 22, n. 38, set.-dez. 2019, p. 210-235 
Meneguzzo, R. - Die Toten (2016) de Christian Kracht

romances para os jornais para que escrevessem resenhas desestabiliza a organização hierárquica entre agentes do campo literário, e tal procedimento pode ser visto como resposta ao escândalo após o lançamento de Imperium, provocado pelo artigo de Georg Diez. O ocorrido ainda contribui para o jogo de "desaparecimento onipresente" do autor, conforme as palavras de Eckhard Schumacher (2019), já que a participação modesta do autor, que em uma das entrevistas nem ao menos toma a palavra diretamente, geram discussões em diversos veículos de imprensa alemã, mantendo o autor presente como tema e não como participante.

Em sua entrevista com Scheck (CHRISTIAN 2016), Kracht aparece vestido conforme a descrição de Nägeli no romance: mesmo terno, mesmo penteado, e, ainda que não use os óculos descritos no romance, os traz no bolso da lapela. Diante de tais semelhanças reforçadas pelo caráter autorreferencial do próprio enredo e pela foto do autor na contracapa do livro, na qual Kracht aparece em uma mansão, local onde Nägeli se estabelece para as filmagens junto com Ida e Amakasu -, o crítico inicia a entrevista questionando a possibilidade de se interpretar Nägeli como a expressão de sentimentos próprios de Kracht, ao que o autor responde prontamente que não. Quando perguntado sobre a estrutura do romance, Kracht explica corretamente as partes do teatro nô, mas inverte o nome das duas primeiras partes - jo e $h a$-, do mesmo modo como Nägeli inverte elementos da citação de Flaubert (1876). Após apresentar os nomes das partes como ha-jo-kyu, Kracht acrescenta "espero estar pronunciando corretamente" e pigarreia, para seguir com a explicação, durante a qual repete apenas o nome $k y u$ em seu lugar correto.

Scheck chama atenção para a cena em que o oficial japonês comete seppuku enquanto é filmado:

DENIS SCHECK: [...] O senhor incorpora à cena uma reflexão, quer dizer, a de que alguém que filma algo do tipo assume uma certa responsabilidade pelo ato de violência. Eu me pergunto, que tipo de responsabilidade tem o escritor que descreve tal cena?

CHRISTIAN KRACHT: Eu acho que apenas o espectador possui essa responsabilidade. [hesita] Que ele não deve assistir algo do tipo, para que isso não se espalhe - apenas o leitor carrega essa responsabilidade, de que ele não deveria ler isso, pelo menos essas partes. (CHRISTIAN 2016)

Kracht se nega a interpretar sua própria obra e se exime de uma resposta satisfatória. De modo irônico, ignora a impossibilidade dos leitores saberem do que se trata a cena até que a leiam, de modo que, obviamente, não poderiam evitá-la. O contentamento de Scheck 
Meneguzzo, R. - Die Toten (2016) de Christian Kracht

com tal resposta, obviamente paradoxal, é criticado por Jürgen Kaube (2016) em um artigo para o jornal Frankfurter Allgemeine. No entanto, tal tipo de procedimento não é a exceção quando se trata do escritor suíço, mas a regra, o que o próprio Scheck reconhece na tréplica no programa Kulturzeit em 7 de setembro de 2016. É interessante notar, também, que Scheck não só aceita as encenações de Christian Kracht, como participa do jogo. Assim, na abertura do programa, vê-se a preparação das câmeras para a entrevista, uma placa chamando a atenção do público para as câmeras de segurança, e os ensaios do entrevistador e do entrevistado, que estabelecem seu posicionamento para a entrevista prestes a começar - em referência à presença das câmeras no romance e ao seu caráter autorrefencial.

Scheck traz à tona o fato de Kracht ser casado com uma diretora de cinema e de ter trabalhado em conjunto no enredo de Finsterworld, para perguntar que relações Kracht vê entre cinema e literatura. Contradizendo a afirmação que fizera a Scheck na entrevista anterior (DENIS 2012), em que afirma que sempre quisera ser pintor - estabelecendo, na época, semelhanças entre sua figura autoral, seu protagonista em Imperium e Adolf Hitler Kracht relata dessa vez que sempre quisera ser diretor de cinema, ao passo que sua esposa sempre quisera ser escritora, reproduzindo o motivo das reflexões em Die Toten.

Na primeira entrevista que concede, ao jornal Der Tagesspiegel, em 2000, Kracht afirma que conversar sobre "conteúdos" sempre leva a equívocos, assim o que resta a fazer é falar para se entreter: "simular, esconder, falar besteira, tudo isso são mecanismos que ainda funcionam bem" (KRACHT 2000). Ainda que tenha mudado aspectos de suas aparições midiáticas e que tenha se afastado da literatura pop e dos autores que fizeram Tristesse Royale com ele, sua encenação ambígua parece ser uma marca constante.

De acordo com Ijoma Mangold (2016), chefe de redação do jornal e autor do artigo publicado no jornal Die Zeit, Kracht conta mais uma vez - como já o fizera em entrevista para a Druckfrisch (DRUCKFRISCH 2009) ou para a LeseZeichen (CHRISTIAN 2015) em entrevistas anteriores - a anedota sobre os túneis existentes nos Alpes Suíços, que deveriam servir de abrigo para a população no caso de um ataque militar. Se tal anedota não é nova, a postura que Kracht parece assumir é. Mangold relata que o termo metafísica é recorrente durante a conversa, e que o autor afirma que "literatura sem uma dimensão metafísica [...] não lhe interessa" (MANGOLD 2016). Desse modo, os autores do pós-guerra que consegue "suportar" seriam Sebald, Handke, Ransmayr, Clemens e Celan. De Heinrich Böll, Irisches Pandaemonium, São Paulo, v. 22, n. 38, set.-dez. 2019, p. 210-235 
Meneguzzo, R. - Die Toten (2016) de Christian Kracht

Tagebuch the parece de valia em virtude de sua busca pelo catolicismo (KRACHT apud MANGOLD 2016). Relata ter visitado a Basílica de São Miniato al Monte com frequência quando morava em Florença: "Quando os monges entoam seus cantos, vestem os mesmos trajes brancos dos monges beneditinos, que nos afrescos da igreja lutam contra o demônio que quer impedir a construção da basílica. [...] Essa é a igreja católica!” (KRACHT apud MANGOLD 2016). Afirma sentir-se uma pessoa melhor após deixar uma igreja, e conta que os afrescos de San Miniato nasceram em um tempo em que “"os horrores da Renascença' ainda não haviam trazido o indivíduo e a personalidade do artista para o centro da perspectiva. 'Mas', interrompe a si próprio, 'o que isso tem a ver com meu romance?"” (MANGOld 2016). Mais adiante desenvolve tal linha de pensamento em mais detalhe: “O trabalho manual também é o Japão. O transvio é a arte, o caminho certo é o trabalho manual. Aquilo que é talhado anonimamente é o ideal. A figura de Cristo, criada apenas para a celebração de Deus. O indivíduo - forget about him" (KRACHT apud MANGOLD 2016). Esse súbito interesse pela transcendência literária e por motivos religiosos reflete o modo como Nägeli se relaciona com o cinema, ou seja, tem tudo a ver com seu romance. Para Nägeli, só há cinco gênios do cinema - ele incluso - que conseguem, através de sua obra, mostrar a presença de Deus (KRACHT 2016a: 39). Se, por um lado, ao recusar verbalmente o culto ao artista e não à obra e ao saturar seu romance de referências, Kracht ressalta que nada é novo e recusa a ideia de um gênio capaz de criar uma obra singular e inaudita, por outro, é através de suas obras e afirmações em entrevistas que ele paradoxalmente chama atenção para si próprio, para seu caráter como artista, como indivíduo. Antes disso, apenas em uma entrevista para a LeseZeichen (KRACHT 2008) havia admitido, após certa hesitação, quando o entrevistador lhe pergunta se acredita em Deus, que é religioso.

Em uma entrevista concedida a Esther Schneider para a Schweizer Radio und Fernsehen (KRACHT 2016b), quando é agraciado com o prêmio suíço de literatura, surpreende com uma atitude diferente da sua costumeira: faz afirmações espontâneas sobre interpretações de sua obra. Afirma que Die Toten não é seu livro favorito, mas que é o que contém mais material biográfico. Comenta que muitas das experiências vividas na infância por Amakasu e Nägeli são calcadas em experiências próprias, pelas quais uma criança passa sem entender plenamente seu sentido ou motivação. Relata ainda que precisou de muito tempo até conseguir escrever sobre tais episódios, que tratam principalmente de humilhação

Pandaemonium, São Paulo, v. 22, n. 38, set.-dez. 2019, p. 210-235 
Meneguzzo, R. - Die Toten (2016) de Christian Kracht

(Demütigung) e degradação (Erniedrigung), que são os temas principais não só desse, mas de todos os seus livros. Conta que escreveu parte do livro na casa de um amigo em Quioto, e que o fato de sua mãe andar pela casa durante a noite colaborou para criar certa atmosfera. Remonta ainda ao tempo em que estudou cinema, como assistia filmes à noite, dormitava por alguns segundos durante o dia, e percebia que, por vezes, imagens dos filmes os quais assistira se misturavam com os breves sonhos que tinha durante tais episódios. Percebeu que os diretores japoneses que menciona no livro, ao lado de Tarkovski, eram os que mais lhe impressionavam, de modo que procurou criar o mesmo efeito através de seu livro: o leitor pode "adormecer" brevemente durante a leitura e acordar após uma ou duas frases, sem que sua leitura seja prejudicada, uma vez que os acontecimentos se desenrolam muito devagar (KRACHT 2016b).

Repentinamente, Kracht parece assumir uma postura sincera em relação à sua obra, e revelar não somente sua intenção ao escrever, mas também detalhes biográficos. Após anos de distanciamento e ironia, nada mais justo que desconfiar de tal posição. Percebe-se, independentemente de seu valor de sinceridade, que essas posições refletem a temática do sonho presente no livro. Suas afirmações e opiniões nas entrevistas que concedeu para seu romance anterior, Imperium, bem como uma foto feita por sua esposa, a diretora de cinema Frauke Finsterwalder, contêm inúmeras alusões ao personagem principal de tal romance. Assim, é lícito assumir que tal posicionamento seja uma forma de referência ao personagem principal de Die Toten, com seu jeito dócil e ingênuo, aparentemente muito autêntico, da mesma forma que se pode assumir que seu desejo de ser diretor de cinema seja referência a esse mesmo personagem.

Essa nova sinceridade tem mais desdobramentos. Entre os dias 15 e 23 de maio de 2018, Kracht confere um ciclo de três palestras na Universidade Goethe, em Frankfurt, que desde a década de 1960 convida autores proeminentes a palestrar sobre sua obra - como Daniel Kehlmann, Ingeborg Bachmann, Heinrich Böll, Bodo Kirchhoff, dentre outros. De modo rotineiro, há sempre cobertura jornalística, por se tratar de um evento importante dentro do universo literário. O que diferencia o evento é a possibilidade de presenciar o autor em sua corporalidade e acompanhar ao vivo alguém a quem, via de regra, só se tem acesso por intermédio de outros veículos, sejam esses sua obra, ou demais paratextos, como entrevistas. A expectativa, no caso de Christian Kracht, portanto, não era pequena, já que o autor é Pandaemonium, São Paulo, v. 22, n. 38, set.-dez. 2019, p. 210-235 
Meneguzzo, R. - Die Toten (2016) de Christian Kracht

conhecido por suas encenações autorais. No entanto, no início da primeira palestra, comunica-se ao público a proibição de se fazer quaisquer registros e pede-se que desliguem seus celulares.

Tal pedido confere um caráter de exclusividade ao evento: apenas os que presenciam o acontecimento têm acesso a ele sem qualquer mediação. Mesmo os presentes, assim, dependem apenas de sua própria memória do ocorrido para narrá-lo - o que evoca temas tratados em Die Toten. Claudia Dürr ressalta em seu texto para o jornal online Geschichte der Gegenwart (DÜRR 2018) que "da experiência compartilhada no anfiteatro derivou-se uma diferença relevante não apenas entre aqueles presentes e ausentes. Também se destacou a diferença entre antes e depois”. O caráter de divisor de águas das palestras se deve ao conteúdo discutido por Kracht. Conforme diversos informes em jornais e revistas, Kracht reinterpreta sua obra à luz de um acontecimento traumático que apenas recentemente lhe volta à memória, isto é, um episódio de abuso sexual vivenciado quando aluno da Lakefield College School, no Canadá. Em 2014, ex-alunos da escola passam a relatar abuso por parte do padre Keith Gleed, capelão entre 1974 e 1980, culminando em alvoroço midiático e investigação policial (FRISCOLANTI 2017).

Dürr nota que a quantidade de publicações sobre o assunto na imprensa é duas vezes maior do que a média para outras palestras em Frankfurt e que as citações diretas que aparecem no Der Spiegel são removidas posteriormente a pedido do próprio autor. A recepção entre jornalistas, de modo geral, é de empatia. Muitos enxergam em seu texto a remissão de seus jogos encenatórios, alguns poucos opinam timidamente a favor da encenação mesmo no ato de confissão, e a maioria concorda que, após o ciclo de palestras, sua obra passa ou deve passar a ser inteiramente reinterpretada. Concordamos que as três palestras fazem parte da encenação autoral de Kracht, sem que isso tenha influência sobre o valor de verdade da confissão, a reduza a um mero jogo encenatório ou desmereça a gravidade do assunto. A confissão faz parte de sua encenação porque é transformada em um texto a ser lido publicamente. Nesse sentido, como paratexto, ela estabelece relações com Die Toten, um romance permeado por violência em que os mortos se presentificam apesar de sua ausência concreta. Assim, mesmo após a morte concreta do algoz, permanece o trauma na vítima; e mesmo após a enunciação do texto de Kracht, ou sua "morte", permanece a narrativa de sua 
Menesuzzo, R. - Die Toten (2016) de Christian Kracht

confissão; finalmente, mesmo após a morte do autor declarada por Barthes (2000), ele permanece.

\section{Considerações finais}

Procuramos, neste artigo, identificar as encenações literárias e autorais do autor suíço Christian Kracht em seu romance Die Toten, publicado em 2016 e, até o momento, não traduzido para o português. A afluência de referências aponta não só para a bagagem cultural do autor - que, principalmente em outros romances, perpassa tanto a alta cultura quanto a cultura popular e de massa - mas também para a condição do texto como um mosaico. Não como uma obra nova, autêntica, inaudita, mas como uma nova configuração para inúmeros outros textos já existentes. Assim como em seus outros romances, o reconhecimento de tais referências não consiste em uma condição para a leitura do romance, mas apresenta um prazer a mais para os leitores que nelas estiverem interessados.

O jogo com a artificialidade toma forma ainda a nível frasal através do uso excessivo de adjetivos. A afluência é tanta que chama a atenção da crítica jornalística, e é ora elogiada, ora execrada. Para Otte (2016), "a construção frasal por vezes complexa demais se transfigura em kitsch complexo de menos". Já para Martin Ebel (2016), como os adjetivos usados são palavras raras ou inventadas, eles reforçam o fato de o romance ser "uma transfiguração do horror para algo elevado, divino". Desse modo, "o seu próprio romance é uma orgia da transfiguração: do normal para o requintado" (EBEL 2016). Os adjetivos parecem contribuir para os deslocamentos de sentido dos substantivos, já que o "cinza" não é apenas cinza, mas "cinza raiado", o "céu" é "nublado" e o "índigo" é "muito profundo", como se constata já na frase de abertura do romance: "[...] o cinza raiado do céu nublado há dias havia se colorido de um índigo muito, muito profundo" (KRACHT 2016a: 11).

O caráter da encenação também fica claro dentro da obra a nível de enredo e de estrutura. A performance sempre teve alguma presença nos romances de Kracht, mas assume sua composição mais elaborada em Die Toten. Através das mídias teatro a cinema, o romance mostra que os pontos de vista são múltiplos e que produzem, com isso, múltiplos sentidos, e o faz se deslocando entre as três mídias, simulando por vezes uma câmera, um espectador ou um narrador onisciente. $\mathrm{O}$ deslocamento constante entre pontos de vista enfatiza o caráter da Pandaemonium, São Paulo, v. 22, n. 38, set.-dez. 2019, p. 210-235 
Meneguzzo, R. - Die Toten (2016) de Christian Kracht

mediação da experiência e a artificialidade da obra. O enredo também inclui um fenômeno paralelo: as passagens que indicam que as personagens estão conscientes de estar em um palco, em um filme, ou em um romance parecem deslocadas do próprio enredo e também enfatizam a artificialidade e o caráter encenatório do romance.

Os acontecimentos relacionados à publicação do romance demonstram que o autor domina as regras do sistema literário e os processos de publicação e de repercussão de um livro, e que é capaz de cumpri-las ou quebrá-las para obter efeitos específicos. O pedido feito pela editora de que os jornais e revistas respeitassem a data de publicação de suas resenhas seguido das entrevistas concedidas por Kracht a Scheck e a Mangold gera tumulto porque desestabiliza o escopo de atuação dos atores envolvidos e os processos normalmente seguidos no meio editorial. Via de regra, os resenhistas jornalísticos se encontram autorizados a elogiar ou criticar uma obra literária, contribuindo para sua recepção do público, e a concorrência entre eles consiste na tentativa de ser o primeiro a publicar material de qualidade. É essa relação que é perturbada, e a motivação para tal estratégia parece ser a tentativa de resposta referente à recepção jornalística de Imperium.

A formação do autor como jornalista e seu interesse pelo new jornalism, que procura explorar a subjetividade em textos que normalmente almejam uma abordagem mais objetiva, já antecipa, de certa forma, estratégias que emprega como romancista. Do mesmo modo, seu envolvimento com o cinema através da parceria com sua esposa e diretora de cinema, em 2013, parece contribuir para a concepção de Die Toten. De modo geral, percebe-se um interesse pelo ponto de convergência entre história e ficção, ou pelo modo como ambas são encenadas pelos sujeitos, observações já feitas, por exemplo, por Erving Goffman em The Presentation of Self in Every Day Life, publicado pela primeira vez em 1956.

Em sua encenação textual, Kracht estabelece relações intertextuais com diversas obras literárias, utiliza a própria obra para criar uma metanarrativa e insere elementos que criam uma estrutura em abismo. Utiliza, ainda, tanto a nível extra quanto intradiegético, elementos do cinema e do teatro que reforçam tanto a metanarratividade quanto o motivo do espelhamento ou reflexão. Além disso, contribuem para suas encenações autorais, criando uma ponte que liga o artista dentro de sua obra, Nägeli, ao artista da própria obra, Kracht. Assim como o autor insere elementos na obra que insinuam semelhanças com sua figura autoral, ele próprio, em sua presença midiática, se encena de forma a estabelecer semelhanças Pandaemonium, São Paulo, v. 22, n. 38, set.-dez. 2019, p. 210-235 
Meneguzzo, R. - Die Toten (2016) de Christian Kracht

com sua personagem. Demonstrou-se isso através de exemplos de afirmações suas em entrevistas ou palestras, e ações conjuntas com a editora que regulam a circulação de sua obra. Diante desse horizonte, procurou-se ilustrar que Kracht direciona suas encenações textuais e autorais - tendo em vista o modo como são recebidas pelo público e pela crítica.

\section{Referências bibliográficas}

BARTELS, Gerrit. Laut schweigen vor Veröffentlichung. In: Der Tagesspiegel, Berlin, 10 set. 2016a, 15:59. Disponível em: https://www.tagesspiegel.de/kultur/christian-kracht-laut-schweigenvor-veroeffentlichung/14528028.html. Acesso em: 06 mar. 2018.

BARTELS, Gerrit. So, wie es niemals gewesen sein wird. In: Der Tagesspiegel, Berlin, 07 set. 2016b, 10:42. Disponível em: http://www.tagesspiegel.de/kultur/die-toten-von-christian-kracht-sowie-es-niemals-gewesen-sein-wird/14509150.html. Acesso em: 06 mar. 2018.

BARTHES, Roland. Der Tod des Autors. In: JANnIDIS, Fotis; LAUER, Gerhard; MARTINEZ, Matias; WinKo, Simone (Ed.). Texte zur Theorie der Autorschaft: Herausgegeben und kommentiert von Fotis Jannidis, Gerhard Lauer, Matias Martinez und Simone Winko. Stuttgart: Philipp Reclam jun., 2000, p. 185-193.

BASKETT, Michael. The attractive empire: transnational film culture in Imperial Japan. Honolulu: University of Hawaii Press, 2008.

BOURDIEU, Pierre. As regras da arte: gênese e estrutura do campo literário. Tradução: Maria Lucia Machado. São Paulo: Companhia das Letras, 1996.

Christian Kracht: "Die Toten", Druckfrisch. 8'49”. ARD. YouTube. 2016. Disponível em: https://www.youtube.com/watch?v=Y3036n9hTXU. Acesso em: 19 jun. 2017.

CHRISTIAN Kracht im Gespräch, LeseZeichen vom 20.10.2008. 7'30”. Bayerischer Rundfunk. YouTube. 2015. Disponível em: https://www.youtube.com/watch?v=6XoAPg4YB4g. Acesso em: 19 jun. 2017.

DENIS Scheck spricht mit Christian Kracht über dessen Buch "Imperium" - DRUCKFRISCH - DAS ERSTE. 10'49”. ARD. YouTube. 2012. Disponível em: https://www.youtube.com/watch?v=cjewDAQdoB0. Acesso em: 19 jun. 2017.

DRUCKFRISCH - Christian Kracht. 7'22”. Bilderfreak. YouTube. 2009. Disponível em: https://www.youtube.com/watch?v=p9qy1HlmPJw. Acesso em: 19 jun. 2017.

DÜRR, Claudia. Dabeisein ändert alles? Die Aufregung um Christian Krachts Poetikvorlesung in der Mediennachlese. In: Geschichten der Gegenwart. Berlin, 15 jul. 2018 Disponível em: https://geschichtedergegenwart.ch/dabeisein-aendert-alles/. Acesso em: 05 abr. 2019.

EBEL, Martin. Ein Schweizer auf Abwegen. In: Tagesanzeiger, Zürich, 09 set. 2016. Disponível em: http://www.tagesanzeiger.ch/kultur/buecher/Ein-Schweizer-auf-Abwegen/story/18376157. Acesso em: 5 jul. 2017.

ENGELS, Bettina. Christian Kracht in Frankfurt: Schutzschild gegen die Erinnerung. In: Tagesspiegel, Berlin, 21 mai. 2018. Dispoível em: https://www.tagesspiegel.de/kultur/christian-kracht-infrankfurt-schutzschild-gegen-die-erinnerung/22586892.html. Acesso em: 28 mai. 2019.

EISNER, Lotte H. The Haunted Screen: Expressionism in the German Cinema and the Influence of Max Reinhardt. Norwich: Thames \& Hudson, 1969.

Flanagan, Damian. Yukio Mishima. London: Reaktion Books, 2014.

Pandaemonium, São Paulo, v. 22, n. 38, set.-dez. 2019, p. 210-235 
Meneguzzo, R. - Die Toten (2016) de Christian Kracht

Flaubert, Gustave. Correspondance. Croisset, 1876. Disponível em: http://flaubert.univrouen.fr/correspondance/conard/lettres/76d.html. Acesso em 07 jul. 2017.

FERGUSON, Robert. Enigma: the life of Knut Hamsun. New York: Farrar, Straus \& Giroux, 1987.

FRANK, Arno. Christian Krachts Frankfurter Vorlesung: Zweifellos kein Eichenlaub. In: Tagesspiegel, Berlin, 26 mai. 2018. Disponível em: https://www.taz.de/ArchivSuche/!5506471\&s=Kracht\%2BPoetikvorlesung/. Acesso em: 28 mai. 2019.

FRANZEN, Johannes. Autorinszenierung. Leistungsfähigkeit und Probleme autorzentrierter Forschung am Beispiel der Studie Posierende Poeten von Alexander M. Fischer. In: GÉvaudAN, Paul; Lautenbach, Hiltrud; Nebrig, Alexander; Schneck, Peter; Scholler, Dietrich (Ed.) PhiN-Philologie im Netz, n. 80, 2017, p. 87-100.

FRISCOLANTI, Michael. How a royal gift exposed sexual abuse at an elite Canadian school. In: Macleans, Toronto, 12 out. $2017 . \quad$ Disponível em: https://www.macleans.ca/news/canada/how-a-royal-gift-exposed-sexual-abuse-at-an-elitecanadian-school/. Acesso em: 05 abr. 2019.

Genette, Gérard. Paratexte: das Buch vom Beiwerk des Buches. Frankfurt: Campus Verlag, 1989. HAUNER, Milan. HItler: A Chronology of his Life and Time. New York: Palgrave Macmillan, 2008.

HöLDERLIN, Friedrich. Hyperion. In: Spiegel Online, Hamburg, 1979. Disponível em: http://gutenberg.spiegel.de/buch/hyperion-264/16. Acesso em 07 set. 2017.

Huston, John. An Open Book. New York: Alfred A. Knopf, 1980.

JOYCE, James. The Dead. In: Dubliners - Webster's German Thesaurus Edition for ESL, EFL, ELP, $T_{O E F L}{ }^{\circledR}, T$ TEIC $^{\circledR}$, and $A P^{\circledR}$ Test Preparation. San Diego: ICON Classics, 2005, p. 170-205.

KAUBE, Jürgen. Christian Kracht bei "Druckfrisch": Publikumstäuschung als Verkaufshilfe. In: Frankfurter Allgemeine Zeitung, Frankfurt, 02 set. 2016, 11:09. Disponível em: http://www.faz.net/aktuell/feuilleton/buecher/themen/christian-kracht-bei-denis-scheckssendung-druckfrisch-14416082.html. Acesso em: 17 nov. 2017.

KEMPKE, Kevin; ZEH, Miriam. Blitz und Donner - Christian Krachts Frankfurter Poetikvorlesungen Als Werkbiographische Zäsur. In: Merkur, Stuttgart, 16 mai. 2018. Disponível em: https://www.merkur-zeitschrift.de/2018/05/16/blitz-und-donner-christian-krachtsfrankfurter-poetikvorlesungen-als-werkbiographische-zaesur/. Acesso em: 28 mai. 2019.

KinoshitA, Akira (Ed.). Kanawa (iron trivet). Disponível em: http://www.thenoh.com/en/plays/data/program_026.html. Acesso em: 06 jul. 2017.

KorfmanN, Michael. Imperium (2012) de Christian Kracht e a questão da auto(r)encenação. Pandaemonium Germanicum, São Paulo, v. 17, n. 23, 2014. p. 83-99. Disponível em: http://dx.doi.org/10.1590/S1982-88372014000100083. Acesso em: 06 mar. 2018.

KRACHT, Christian. Christian Kracht im Gespräch: der schlechteste Journalist von Allen. [Entrevista ]. Der Tagesspiegel online, Berlin, 30 jun. 2000. Disponível em: http://www.tagesspiegel.de/kultur/christian-kracht-im-gespraech-der-schlechtestejournalist-von-allen/151028.html. Acesso em: 19 jun. 2017.

Kracht, Christian. Die Toten. Köln: Kiepenheuer \& Witsch, $2016 \mathrm{a}$.

KRACHT, Christian. Schweizer Buchpreis: der Gewinner Christian Kracht im Interview. [Entrevista cedida a ] Esther Schneider. Schweizer Radio und Fernsehen online, Zürich, 13 nov. 2016b. Disponível em: https://www.srf.ch/sendungen/52-beste-buecher/schweizer-buchpreis-dergewinner-christian-kracht-im-interview. Acesso em: 19 jun. 2017.

KulturZEIT. Kulturzeit-Gespräch mit Denis Scheck, Mainz, 07 set. 2016. Emissora: 3sat. Disponível em: https://www.3sat.de/kultur/kulturzeit/kulturzeit-gespraech-mit-denis-scheck-100.html. Acesso em: 29 mai. 2019.

Pandaemonium, São Paulo, v. 22, n. 38, set.-dez. 2019, p. 210-235 
Meneguzzo, R. - Die Toten (2016) de Christian Kracht

LEITER, Samuel L. Historical dictionary of japanese traditional theatre. Maryland: Scarecrow Press. 2006.

MANGOLD, Ijoma. Christian Kracht: ich bin ein schlimmer Nostalgiker. In: Die Zeit online, Hamburg, 11 out. 2016. Disponível em: http://www.zeit.de/2016/37/die-toten-roman-christian-kracht. Acesso em: 17 nov. 2017.

MAnN, Thomas. Morte em Veneza. Tradução: Eloísa Ferreira Araújo Silva. Berlin: Fischer Verlag, 2003.

MishimA, Yukio. Patriotism. In: Death in midsummer and other stories. New York: Penguin Books in association with Martin Secker \& Warburg, 1977, p. 102-127.

MishimA, Yukio. Yukoku or the rite of love and death. Tokyo: Toho Company, 1966.

OTTE, Carsten. Dompteur des Bösen. In: SWR2, Baden-Baden, 8 set. 2016. Disponível em: https:/www.swr.de/swr2/kultur-info/buchkritik-die-toten-von-christian-kracht/$/ \mathrm{id}=9597116 / \mathrm{did}=18098012 / \mathrm{nid}=9597116 / \mathrm{dg} 8 \mathrm{gk1} / \mathrm{index} . \mathrm{html}$. Acesso em: 5 jul. 2017.

RINIKER, Christine. "Die Ironie verdampft ungehört": implizite Poetik in Christian Krachts Die Toten (2016). In: RINIKER, Christine; LORENZ, Matthias N. (Ed.) Christian Kracht revisited: Irritation und Rezeption. Berlin: Frank \& Timme, 2018. p. 71-119.

SCHUMACHER, Eckhart. Omnipräsentes Verschwinden. In: BIRGFELD, Johannes; CONTER, Claude D. (Ed.). Christian Kracht: Zu Leben und Werk. Köln: Kiepenheuer \& Witsch, 2009, p. 187203.

SIEREK, Karl. Der lange Arm der Ufa: Filmische Bilderwanderung zwischen Deutschland, Japan und China 1923-1949. Wiesbaden: Springer VS, 2018.

StoKes, Henry Scott. The life and death of Yukio Mishima. New York: Cooper Square Press, 2000.

THE LEWISTON DAILY SUN, 20. set. 1932. Disponível em: https://news.google.com/newspapers?nid=1928\&dat=19320920\&id=9oApAAAAIBAJ\&sji d=gmYFAAAAIBAJ\&pg=3051,5949013. Acesso em: 25 jun. 2017.

TUCHEL, Johannes. Nikolaus Graf von Üxküll-Gyllenband. In: Gedenkstätte deutscher Widerstand. Berlin, 2016. Disponível em: http:/www.gdwberlin.de/vertiefung/biografien/personenverzeichnis/biografie/view-bio/nikolaus-graf-vonuexkuell-gyllenband/?no_cache=1. Acesso em: 25 jun. 2017.

Recebido em 05 de abril de 2019 Aceito em 02 de maio de 2019

Pandaemonium, São Paulo, v. 22, n. 38, set.-dez. 2019, p. 210-235 